Graduate Journal of Food Studies • Volume 5, Number 2

\title{
Architecture and the Art of Dining: The Performance of Dining in Early America
}

\section{Morgan Flaherty}

Published on: Dec 11, 2018

DOI: $10.21428 / 92775833.5441 \mathrm{e} 8 \mathrm{f9}$

License: Creative Commons Attribution 4.0 International License (CC-BY 4.0). 


\section{Bernard Herman, Town House: Architecture and Material Life in the Early American City, 1780-1830, Chapter Two: “The Merchant Family's House" (Chapel Hill: University of North Carolina, 2005).}

Webs of spun sugar formed into globes with small flowers nestled inside, stacked upon one another atop a silver cake stand and surrounded by baskets, also made of spun sugar. This image of an edible centerpiece in eighteenth-century Virginia conjures dazzling images of reflective candlelight and intimate talk at the dining table, including compliments to the host from impressed guests. Although it appears in a book on architecture and material culture, this scene also fits into the field of food studies. Displays of dessert in elite households can inform our understanding of historical cooking techniques, knowledge of the creators and consumers of the dessert, and uses of food spaces in the past. Bernard Herman's Town House (2005) analyzes the architecture of an elite house in Norfolk, Virginia and identifies spaces where food was prepared and consumed to illustrate new modes of gentility in late eighteenth- and early nineteenth-century Virginia. Its interdisciplinary approach incorporating architectural history, material culture, and the performance of dining make it a valuable resource to the field of food studies.

Herman approaches architecture and material culture by way of food in Chapter 2 titled, "The Merchant Family's House." In it, he illustrates the performance of dessert at the dinner table through comparison with the architectural performance of the home. Herman introduces an impressive and complicated recipe for sugar globes, which comes from a recipe book in the Myers family papers (Moses Myers was a wealthy merchant with an import/export business who built his home in Norfolk, Virginia in 1797).[1] Herman also walks the reader through the spaces involved in the construction of the edible masterpiece: the kitchen, and the most important space, the dining room. He argues that dining was a performance and a space for peer-to-peer judgment, and he places food at the same level of social influence as other material goods and architecture, which, collectively, illustrate a given family's elite status. All the while, he supports his argument by referring to household inventories with foodrelated objects.

The field of food studies could benefit from a close study of Herman's research into the Myers family papers. The Myers family papers include a recipe book from Elizabeth Raffald, titled The Experienced English Housekeeper (1786), which includes a dogeared page on the recipe for "a Desert of Spun Sugar."[ㄹ] Herman categorizes the multitude of dog-eared recipe books in the personal collection as "exceptional, 
ephemeral, and labor-intensive."[]ㅡ He connects the elaborate sugar masterpieces, commissioned by Elizabeth Myers (the wife of Moses Myers) and carried out by her servants, to her mastery of the domain that was the dining room. Her oversight of dining entertainment full of whimsical sugar centerpieces reveals not only one of her responsibilities as household manager but also her use of it to demonstrate control over her household.

Herman argues that dining was a performance with guests as the audience. The social atmosphere of a genteel household created an opportunity for upward mobility for the host family. As a merchant family, the Myers had access to imported goods plus enough disposable income to purchase the material objects and ingredients necessary to make and present confections. As a collection, the Myers family recipe books, grocery lists, and inventories are an unusual find, given the eighteenth-century documentation available today. While inventories are relatively common in the archives, it is a valuable to know the exact recipe books that the Myers owned. The collection as a whole, in addition to other early recipe books, should be considered starting points for future historical research.

The interdisciplinary approach of Herman's work strengthens his explanation of social behaviors associated with gentility. Architectural analysis and consideration of material culture enhance the documentary record. Floor plans of houses, analysis of hearth spaces, material objects used for food preparation and serving, as well as archaeology, all inform his understanding of historic foodways. Herman's use of architectural evidence outside the traditional written record also helps to shed light on the servants and enslaved working in these spaces. These individuals created the feasts presented at the dinner table. Focusing on the kitchen as a space for the creation of food can bring more attention to the people who worked in that space.

This essay looks at the case study of sugar and displays of confection in the Myers house in the work of Bernard Herman, who builds on the influential scholarship of Sidney Mintz. In Sweetness and Power (1985), Mintz traces the history of sugar to its earliest origins and discusses how eating habits and tastes changed as sugar became a dominant crop. He compares the power of the producers and consumers of sugar by looking at demand in Europe. He argues that sugar took on new social meanings and became a symbol of luxury which eventually transitioned into a more commonplace staple. Mintz connects the importation of enslaved Africans to the Caribbean from the early sixteenth century to the competition between European nations to dominate 
sugar production.[4]] Herman expands upon these ideas by incorporating material culture and architecture into the study of sugar displays as social performance.

The theme of food as a performance is not a new to food studies, but the field would benefit from a historical approach to it. Combining close study of material culture, physical space, and archaeology paints a fuller picture than simply close reading documentary evidence. The primary sources cited in Herman's work provide a guide for future research on eighteenth-century dining practices and the variety of food purchased and served by a wealthy merchant household in Norfolk, Virginia. Herman's view into the Myers household suggests that, historically, food served as a social performance for the elite, enabled by the food itself, the enslaved who produced it, those who consumed it, and the spaces in which it was eaten.

\section{Biography}

Morgan Flaherty is an MA student in History at the University of Maryland, College Park. Her experience at Colonial Williamsburg as an intern in the Historic Foodways Division inspired her current research on foodways in the eighteenth-century Atlantic World. Her research focuses on displays of confection and material culture related to dessert presentations. She received her BA in American Studies from The College of William and Mary.

\section{Citations}

1. “The Myers Family," Chrysler Museum of Art, accessed November 18, 2018, http://www.chrysler.org/about-the-museum/historic-houses/the-moses-myershouse/the-myers-family $\perp . \pm$

2. Bernard Herman, Town House: Architecture and Material Life in the Early American City, 1780-1830 (Chapel Hill: University of North Carolina Press, 2005), 3334. $\doteq$

3. Herman, Town House, 34.

4. Sidney Mintz, Sweetness and Power: The Place of Sugar in Modern History (New York: Viking, 1985), 31-36. 